\title{
The Impact of Plug-in Electric Vehicles on Distribution Network
}

\author{
Kaida Feng \\ Yangjiang Power Supply \\ Bureau \\ Guangdong Power Grid \\ Co., Ltd \\ Yangjiang, China \\ 38552445@qq.com
}

\author{
Yanling Zhong \\ Department of Electrical \\ Engineering \\ Guangdong University of \\ Technology \\ Guangzhou, China \\ zhongyl@mail2.gdut.edu.cn \\ Chun Sing Lai \\ Brunel Institute of Power \\ Systems \\ Brunel University \\ London \\ London, UK \\ chunsing.lai@brunel.ac.uk
}

\author{
Binzhuo Hong \\ Yangjiang Power Supply \\ Bureau \\ Guangdong Power Grid \\ Co., Ltd \\ Yangjiang, China \\ binjoyhong@163.com
}

\author{
Chenchen Bai \\ Department of \\ Mathematics \\ Southern University of Science \\ and Technology \\ Shenzhen, China \\ 11811833@mail.sustech.edu.cn
}

\author{
Xiaomei Wu \\ Department of Electrical \\ Engineering \\ Guangdong University of \\ Technology \\ Guangzhou, China \\ epxm_wu@gdut.edu.cn
}

\begin{abstract}
With concerned environmental problem, a large number of electric vehicles (EVs) has been adopted to replace the oil-fueled vehicles. If electric vehicles are charged simultaneously on a large-scale, it may cause peak load increase. Therefore, it is of great practical significance to study the influence of controlled charging behavior of electric vehicles on power grid. Firstly, Gaussian Mixture Model is used to modeling electric vehicles. Secondly, Monte Carlo method is studied to determine the charging load of electric vehicles, and the influence of uncontrolled charging of electric vehicles on the power grid is analyzed. Then the peak and valley hours are divided according to the membership function and the time-of-use pricing to minimize the difference between peak and valley load. Furthermore, the influence of controlled charging of EVs on power grid is analyzed. Finally, the model is applied to simulate and analyze the distribution network of Yangjiang, a coastal city in South China. The case study shows that the uncontrolled charging of EVs will increase the peak load of the power grid. The proposed controlled charging strategy can effectively transfer the charging load of EVs and lessen peak load demand.
\end{abstract}

Keywords-electric vehicles (EVs), Monte Carlo method, controlled charging, membership function, time-of-use pricing

\section{INTRODUCTION}

Today, with the global warming and energy crisis and other issues, low-carbon life has become the consensus of everyone [1]. Due to its low pollution and low noise characteristics, electric vehicles (EVs) are gradually favored by people and become the preferred tool for low-carbon travel. Since EV charging needs to be connected to the power grid to obtain electricity, large-scale charging may cause overload and safety of the power grid. Therefore, it is of great importance to study the impact of controlled EV charging on the power grid. Although researchers have done some related work on the impact of EV charging on the power grid [2-3], there has no general applicable method. References [4] and [5] report the impact of different charging strategies on the distribution networks of Germany and New Zealand, respectively. In [6], an unsupervised algorithm is proposed to extract the local EV charging load. This algorithm can effectively reduce the interference of other similar charging behaviors and make power grid decisions more intelligent. In [7], the authors proposed a charging strategy based on cost-benefits analysis, which aims to minimize daily production costs and peak-to-average ratio (PAR). The method can be applied to small and medium distribution networks. In [8], some current controlled charging methods and strategies are reviewed and their advantages and disadvantages are analyzed. Reference [9] proposes a model to quantify the benefits of controlled charging to the power grid. The model is verified through the load data of three million electric vehicles in California, which proves that the model is effective. Reference [10] compares the cost and benefits of decentralized and centralized algorithms in large-scale power systems, so as to improve the strategies of Plug-in Electric Vehicle (PEV) smart charging. In [11], the authors proposed a new PEV smart charging method, which can determine different charging modes based on factors such as vehicle type and driver habits, so that both the power grid and vehicle owners can benefit from it.

However, most existing strategies include the consideration of the impact of large-scale uncontrolled charging of electric vehicles on the power grid. Even some works considered controlled EV charging, they only comparatively analyzed the impact of controlled and uncontrolled charging on the entire load curve of the power grid. This paper provides a controlled charging management of electric vehicles plugged in the power grid. We firstly use the Monte Carlo method to simulate the charging load of EVs. And then, the peak and valley time periods are divided by the membership function. Next, the 
TABle I. Electric Private Vehicle Plug-IN Time

\begin{tabular}{|c|c|c|}
\hline Duration & Charging time (s) & Percent \\
\hline $0: 00-8: 00$ & 7723 & $19.08 \%$ \\
\hline $8: 00-14: 00$ & 10746 & $26.55 \%$ \\
\hline $14: 00-17: 00$ & 7438 & $18.38 \%$ \\
\hline $17: 00-19: 00$ & 4654 & $11.50 \%$ \\
\hline $19: 00-22: 00$ & 6205 & $15.33 \%$ \\
\hline $22: 00-24: 00$ & 3701 & $9.15 \%$ \\
\hline
\end{tabular}

TABLE II. ElECtric Private Vehicle Charging QUANTITY

\begin{tabular}{|c|c|c|}
\hline Charging quantity & Charging time (s) & Percent \\
\hline $0-10 \mathrm{kWh}$ & 5277 & $12.92 \%$ \\
\hline $10-20 \mathrm{kWh}$ & 115554 & $28.55 \%$ \\
\hline $20-30 \mathrm{kWh}$ & 8941 & $22.09 \%$ \\
\hline $30-40 \mathrm{kWh}$ & 8181 & $20.22 \%$ \\
\hline $40-60 \mathrm{kWh}$ & 5737 & $14.18 \%$ \\
\hline $60-80 \mathrm{kWh}$ & 827 & $2.04 \%$ \\
\hline
\end{tabular}

consumer psychology model is used to optimize the time-of-use electricity price, with the minimum peak-valley load difference as the objective. Finally, the impact of electric vehicles on the entire load curve under controlled and uncontrolled charging is analyzed.

The rest of this paper is organized as follows. Section II models the charging load of EVs. Section III develops uncontrolled charging for EVs. Controlled charging strategy is depicted in Section IV, and the conclusion is provided in Section V.

\section{Modelling Electric VehicLes}

The charging load calculation of electric vehicles is related to many factors, in which the charging scale and charging characteristics of EVs are the main factors that affect the calculation results of charging loads. The charging scale of EVs refers to the number of different types of electric vehicles, and the charging characteristics include charging mode, state-ofcharge, and the charging demand. In this work, the charging data of electric vehicles are collected from a coastal city in South China, and the main types of electric vehicles in characteristics of private vehicles and buses are quite different. Private vehicles are mainly used to meet personal daily travel needs with low charging frequency and small charging demand, while the daily mileage of the bus is larger and the charging demand is greater. Therefore, it is necessary to establish charging models to determine the charging load under various conditions.

\section{A. Electric Private Vehicle Modelling}

Table I and Table II show the statistical results of plug-in time and charging demand of electric private vehicles respectively where the collecting number of chargers is 141 and the number of vehicles is 7135 . Charging data of private vehicles come from public charging station and charging spots in residential areas. Some of these charging stations are located near residential areas, while most of them are located in power stations near enterprises and public institutions. It can be seen that in Yangjiang residential areas, many users choose to charge their cars at work during the day. Since charging spots have not

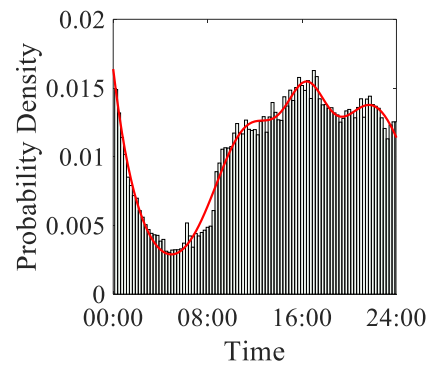

(a) Plug-in time

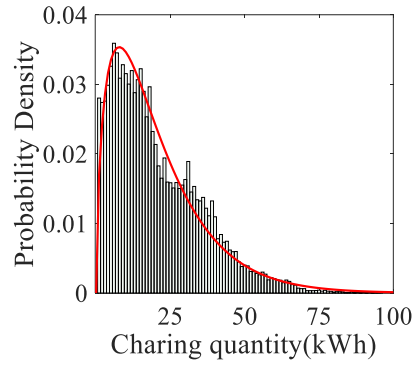

(b) Charging quantity
Fig. 1. The plug in time and charging quantity of electric private vehicles.

been installed in many residential areas, users mainly choose to charge their cars after work or at night. At present, the battery capacity of private vehicles is mainly between $50-70 \mathrm{kWh}$, while a small number of private vehicles have a battery capacity of $80 \mathrm{kWh}$, so the charging quantity of private vehicles is mainly between $10-60 \mathrm{kWh}$.

The probability density function (PDF) of charging demand for electric vehicles is not described accurately by a single distribution function. In this paper, multiple distribution functions are considered to jointly describe the PDF characteristics of charging demand.

The charging demand analysis of EV based on PDF method can refer to the gray image processing technology. The image gray histogram reflects the frequency of gray value at a certain level in the image, which can also be considered as the estimation of the gray probability density of the image. The histogram of charging demand variation reflects the probability density estimation of plug-in time and charging quantity. The Gaussian Mixture Model (GMM) is widely used in the modeling of grayscale image processing. In this paper, the GMM is tried to describe the probability density distribution characteristics of charging demand.

The mathematical model of GMM is

$$
f(x)=\sum_{i=1}^{n} a_{i} \cdot e^{\left(\frac{x-b_{i}}{c_{i}}\right)^{2}}
$$

where $a_{i}, b_{i}$ and $c_{i}$ are the distribution parameters of the model, which can be obtained by maximum likelihood estimation.

According to the summary of plug-in time and charging quantity discussed above, Fig. 1 (a) presents the probability distribution of the probability distributions of plug-in time of electric private vehicles and Fig. 1 (b) presents the probability distribution of charging quantity of electric private vehicles. Fig. 1 (a) can be modelled by GMM, and Fig. 1 (b) can be modelled by Gamma distribution as follows:

$$
f(x, \beta, \alpha)=\frac{\beta^{\alpha}}{\Gamma(\alpha)} x^{\alpha-1} e^{\beta x}
$$

where $\alpha$ and $\beta$ are the distribution parameters of the model. The corresponding PDFs parameters are summarized in Table III. 
TABLE III. Plug-IN TIME AND CHARGING QUANTITY OF PRIVATE VEHICLES AND ELECTRIC BUSES

\begin{tabular}{|c|c|c|c|}
\hline & Charging period & Plug-in time & Charging quantity \\
\hline \multirow{4}{*}{ Electric private vehicles } & \multirow{4}{*}{ 00:00-24:00 } & $a_{1}=0.00728, b_{1}=65.63, c_{1}=9.539$ & \multirow{4}{*}{$\begin{array}{c}\text { Gamma distribution } \\
\alpha=1.6163 \\
\beta=12.6565\end{array}$} \\
\hline & & $a_{2}=3.181 * 10^{11}, b_{2}=-545.3, c_{2}=98.58$ & \\
\hline & & $a_{3}=0.01365, b_{3}=87.38, c_{3}=20.21$ & \\
\hline & & $a_{4}=0.01202, b_{4}=46.81, c_{4}=17.75$ & \\
\hline \multirow{11}{*}{ Electric buses } & \multirow{3}{*}{ 00:00-06:00 } & $a_{1}=1.267, b_{1}=-184.1, c_{1}=111.7$ & \multirow{11}{*}{$\begin{array}{l}a_{1}=0.01396, b_{1}=39.29, c_{1}=93796 \\
a_{2}=0.03079, b_{2}=23.85, c_{2}=3.621 \\
a_{3}=0.23590, b_{3}=12.70, c_{3}=11.08 \\
a_{4}=0.20810, b_{4}=12.09, c_{4}=11.04\end{array}$} \\
\hline & & $a_{2}=0.02907, b_{2}=120.6, c_{2}=68.26$ & \\
\hline & & $a_{3}=0.02299, b_{3}=236.2, c_{3}=83.03$ & \\
\hline & \multirow{2}{*}{ 06:00-12:00 } & $a_{1}=0.01576, b_{1}=698.8, c_{1}=62.70$ & \\
\hline & & $a_{2}=0.01086, b_{2}=523.9, c_{2}=86.85$ & \\
\hline & \multirow{2}{*}{$12: 00-16: 00$} & $a_{1}=0.01480, b_{1}=762.1, c_{1}=78.89$ & \\
\hline & & $a_{2}=0.01060, b_{2}=862.0, c_{2}=116.5$ & \\
\hline & \multirow{4}{*}{$16: 00-24: 00$} & $a_{1}=0.12290, b_{1}=1328, c_{1}=10.64$ & \\
\hline & & $a_{2}=0.01547, b_{2}=1439, c_{2}=51.90$ & \\
\hline & & $a_{3}=0.00787, b_{3}=1272, c_{3}=12.58$ & \\
\hline & & $a_{4}=0.00457, b_{4}=1068, c_{4}=128.9$ & \\
\hline
\end{tabular}

TABLE IV. EleCtric Buses Plug-in Time

\begin{tabular}{|c|c|c|}
\hline Duration & Charging time (s) & Percent \\
\hline $0: 00-8: 00$ & 39595 & $48.35 \%$ \\
\hline $8: 00-14: 00$ & 19125 & $23.35 \%$ \\
\hline $14: 00-17: 00$ & 6207 & $7.58 \%$ \\
\hline $17: 00-19: 00$ & 2070 & $2.53 \%$ \\
\hline $19: 00-22: 00$ & 1541 & $1.88 \%$ \\
\hline $22: 00-24: 00$ & 13359 & $16.31 \%$ \\
\hline
\end{tabular}

TABLE V. Electric Buses Charging QuANTITY

\begin{tabular}{|c|c|c|}
\hline Charging quantity & Charging time (s) & Percent \\
\hline $10-30 \mathrm{kWh}$ & 5652 & $6.90 \%$ \\
\hline $30-60 \mathrm{kWh}$ & 24999 & $30.52 \%$ \\
\hline $60-90 \mathrm{kWh}$ & 31340 & $38.27 \%$ \\
\hline $90-120 \mathrm{kWh}$ & 11044 & $13.48 \%$ \\
\hline $120-150 \mathrm{kWh}$ & 8088 & $9.88 \%$ \\
\hline $150-180 \mathrm{kWh}$ & 774 & $0.95 \%$ \\
\hline
\end{tabular}

\section{B. Electric Bus Modelling}

Table IV and Table V show the statistical results of plug-in time and charging quantity of electric buses respectively. Since most buses in Yangjiang operate until 22:00, the number of charging buses increases sharply after 22:00. Some buses that are not charged at night choose to be charged during the day to maintain normal daily operation. As the battery capacity of buses is larger than that of private vehicles, it can be seen from Table II and Table IV that the charging quantity of buses is larger, mainly within the range of $30 \mathrm{kWh}-120 \mathrm{kWh}$. Unlike private vehicles, buses have specific operating time and time headways, so the probability distribution of their plug-in time is relatively complicated, which requires piecewise fitting. The result of piecewise fitting is shown in Fig. 2.

The probability density functions of charging quantity for electric buses is shown in Fig. 3.
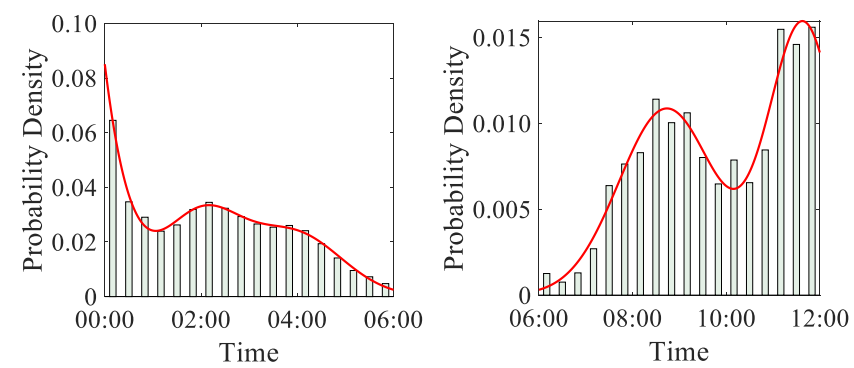

(a) 00:00-06:00

(b) 06:00-12:00
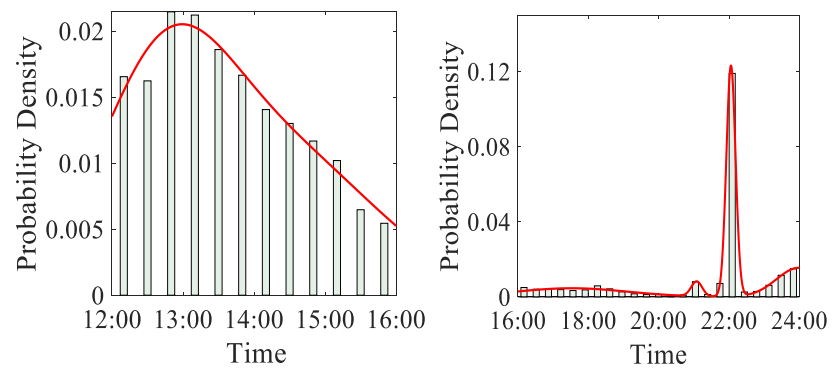

(a) 12:00-16:00

(b) 16:00-24:00

Fig. 2. The plug-in time of buses.

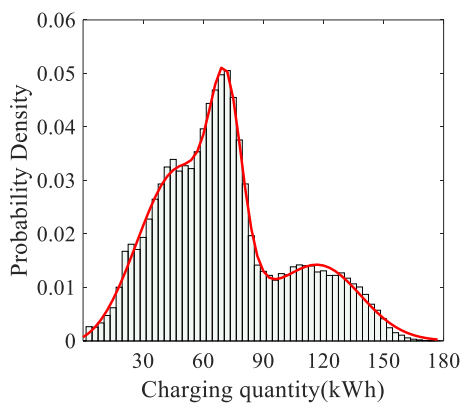

Fig. 3. The charging quantity of electric buses. 
TABLE VI. PREDICTION OF VeHICLE PARC IN YANGJIANG

\begin{tabular}{|c|c|c|c|c|c|c|}
\hline Vehicle types & $\mathbf{2 0 1 5}$ & $\mathbf{2 0 1 6}$ & $\mathbf{2 0 1 7}$ & $\mathbf{2 0 1 8}$ & $\mathbf{2 0 1 9}$ & $\mathbf{2 0 2 0}$ \\
\hline Bus & 302 & 348 & 400 & 460 & 530 & 610 \\
\hline Taxi & 677 & 719 & 719 & 719 & 719 & 719 \\
\hline $\begin{array}{c}\text { Goods truck/ } \\
\text { Sanitation } \\
\text { vehicle }\end{array}$ & 922 & 1010 & 1107 & 1213 & 1329 & 1456 \\
\hline Utility vehicle & 2500 & 2517 & 2533 & 2550 & 2567 & 2584 \\
\hline Private vehicle & 197030 & 247213 & 310177 & 389177 & 488299 & 612677 \\
\hline Total & 201431 & 251806 & 314936 & 394120 & 493444 & 618035 \\
\hline
\end{tabular}

TABLE VII. PREDICTION OF EV PARC IN YANGJIANG

\begin{tabular}{|c|c|c|c|c|c|c|}
\hline Vehicle types & $\mathbf{2 0 1 5}$ & $\mathbf{2 0 1 6}$ & $\mathbf{2 0 1 7}$ & $\mathbf{2 0 1 8}$ & $\mathbf{2 0 1 9}$ & $\mathbf{2 0 2 0}$ \\
\hline Bus & 99 & 140 & 198 & 261 & 334 & 417 \\
\hline Taxi & 0 & 5 & 5 & 5 & 405 & 405 \\
\hline $\begin{array}{c}\text { Goods truck/ } \\
\text { Sanitation } \\
\text { vehicle }\end{array}$ & 0 & 13 & 31 & 54 & 86 & 131 \\
\hline Utility vehicle & 0 & 3 & 7 & 12 & 18 & 25 \\
\hline Private vehicle & 1 & 177 & 680 & 1747 & 3680 & 6913 \\
\hline Total & 100 & 339 & 922 & 2080 & 4524 & 7892 \\
\hline
\end{tabular}

According to the summary of plug-in time and charging quantity discussed above, Fig. 2 and Fig. 3 present the probability distributions of electric buses. The corresponding PDFs parameters are summarized in Table III.

\section{UnCONTROLLED CHARGING}

\section{A. Calculation of EV Charging Load Based on MCS}

Monte Carlo simulation is a random simulation method to study probabilistic phenomena. The approximate results are calculated on the basis of random sampling. With the increase of sampling times, the probability of getting correct results increases gradually. The stochastic process of Monte Carlo method can be divided into three steps:

1) Model: Construct a probabilistic model.

2) Sample: Take a random sample from a given probability distribution.

3) Result: Obtain an approximate result.

According to the Statistical Yearbook of Guangdong Province 2019, the vehicle PARC of Yangjiang in 2018 was 371,917 , including 352,874 private cars and 449 public buses [12]. In its 13th Five-Year Plan, Yangjiang Development and Reform Bureau predicted that the number of vehicles in 2018 would be 394,120 , where 389,177 private cars and 460 public buses. By 2020, the population will reach 618,035 , including 612,667 private cars and 610 public buses [13]. As shown in Table VI, the vehicle PARC of Yangjiang during the 13th FiveYear Plan period has been growing rapidly in recent years, of which the main increment is from private passenger cars, which will increase by nearly twice in 2020 compared to that in 2015 .

Electric vehicles will be fully promoted as a national target in the future in China. As shown in Table VII, the electric vehicles PARC predicted by Yangjiang Development and Reform Commission during the 13th Five-Year Plan period shows that Yangiiang will firstly promote and develop public

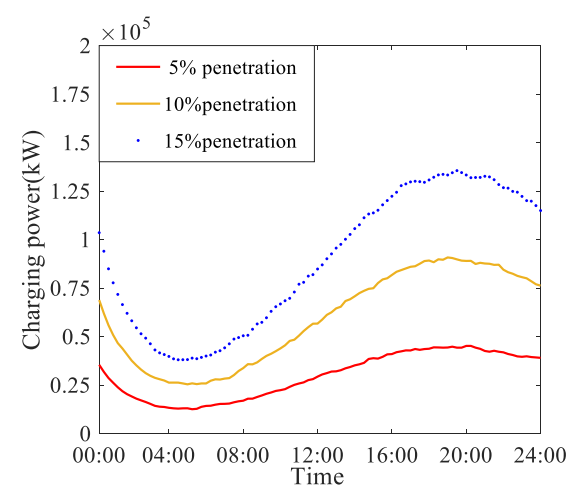

Fig. 4. Charging load of private vehicles.

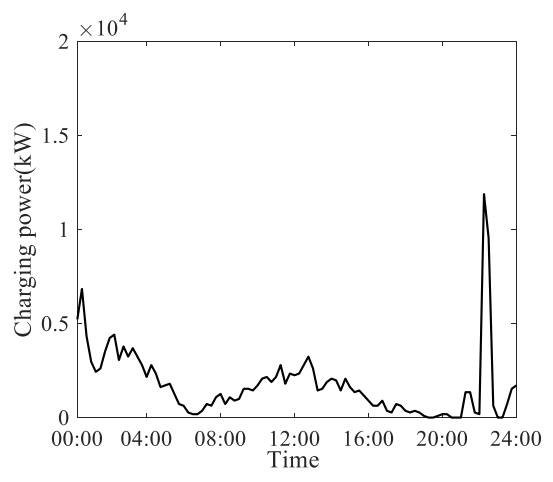

Fig. 5. Charging load of buses.

transport and official vehicles, and then shift its focus to private vehicles [13].

It is predicted that the penetration rate of electric vehicles on public buses in Yangjiang will reach $68.4 \%$ in 2020, much higher than that of private cars, which is $1.1 \%$. Since the base number of private cars is much higher than that of other types of vehicles, the larger penetration rate of electric private cars in the future will impact power grid greater.

Assuming that the total number of private vehicles and public buses will be 610,000 and 1,000 respectively in 2020.The charging power of the fast charging spot for private vehicles is $42 \mathrm{~kW}$, and $7 \mathrm{~kW}$ for slow charging spot. Also the charging power of the public buses is $70 \mathrm{~kW}$. The fast charging ratio of the private vehicles' charging spots is $13.5 \%$ and the slow charging is $76.5 \%$. Using Monte Carlo simulation the charging load curve of the private vehicles is shown in Fig. 4. If all buses use fast charging, the obtained charging load curve of the bus is shown in Fig. 5.

\section{B. Results}

As seen from Fig. 5, the charging peak demand of the private vehicle is between 19:00 to 21:00. During this period, most owners of electric private cars go home from work then the electric vehicles may be charged. The charging demand of the private vehicles is low between 7:00 and 9:00, when most of the electric vehicles have been out of charging for going to work. This shows that the charging demand of private vehicles is affected by the human's activity. The charging demand of the buses is relatively large during the daytime, and the charging 


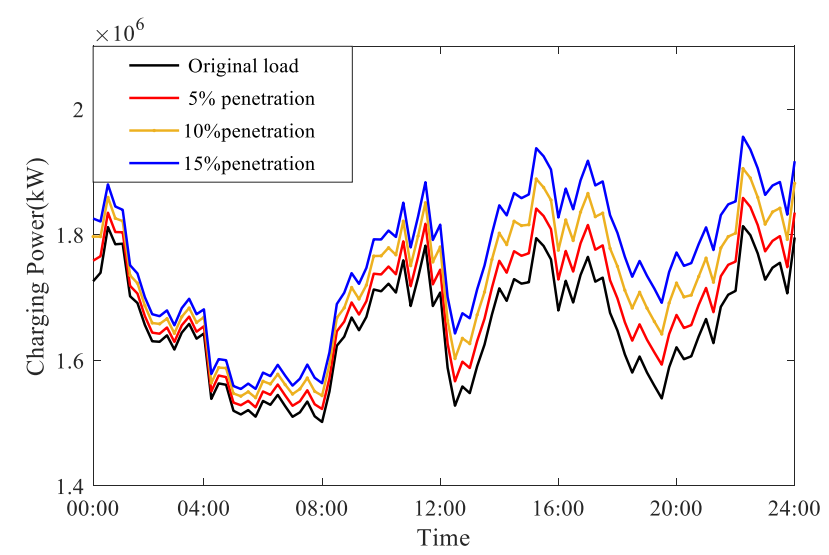

Fig. 6. Load curve of the region considering the uncontrolled charging load during the day.

peak demand appears between 22:00 and 23:00, which can be seen from Fig. 5. Adding the uncontrolled charging load of electric private vehicles and electric buses to the typical daily load profile in Yangjiang, the results are shown in Fig. 6. Three cases are conducted, in which electric private vehicle penetration rates are $5 \%, 10 \%$, and $15 \%$.

As seen from Fig. 6, the uncontrolled charging of electric vehicles will bring an extra peak load to the regional power grid, which increases the weakness of the power supply. With the penetration rate of electric private vehicles increases, this phenomenon will become more obvious.

\section{Controlled Charging}

In the previous section, the charging of the EVs starts randomly. Optimization algorithms will be used to achieve peak-shaving and valley-filling effect on the typical daily power load curve.

\section{A. Peak Hours and Valley Hours Division based on Membership Function}

Time-of-use electricity price is an important strategy to achieve controlled charging [14]. The load curve of one day can be divided into three periods: peak, flat and valley, as shown in Table VIII with an explanation given later. The electricity price in each period is different, which provides the user to select the optimal charging period, to reduce the peak-to-valley difference of power loads. For electric vehicles, the smart charging strategy is to guide charging during valley hours, reducing the pressure of power supply during peak hours and improving the stability of the power system.

The membership function (MF) represents the degree of the belongingness of the element $x$ to a fuzzy set. MF is a common method used to divide the peak-valley hours of the load, which includes a partial small half trapezoid function and a partial large half trapezoid function. They are used to determine the peak hours membership degree and valley hours membership degree of the load and can be calculated by

$$
\left\{\begin{array}{l}
y_{1}(x)=\frac{A-x}{A-B} \\
y_{2}(x)=\frac{x-B}{A-B}
\end{array}\right.
$$

TABLE VIII. PEAK AND VALLEy HOURS Division

\begin{tabular}{|c|c|}
\hline Period & Time \\
\hline \multirow{2}{*}{ Peak } & $00: 00-01: 00,09: 30-11: 45$, \\
& $15: 00-16: 45,21: 45-23: 45$ \\
\hline \multirow{2}{*}{ Valley } & $04: 00-08: 00,12: 00-13: 00$, \\
& $18: 00-20: 30$ \\
\hline \multirow{2}{*}{ Flat } & $01: 15-03: 45,08: 15-09: 15$, \\
& $13: 15-14: 45,17: 15-17: 45$, \\
& $20: 45-21: 30$ \\
\hline
\end{tabular}

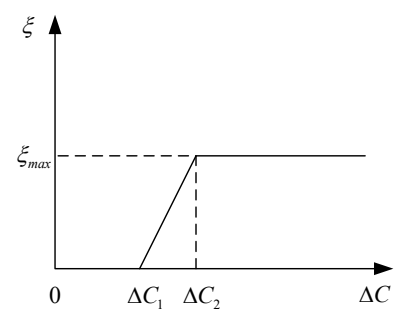

Fig. 7. Load transfer curve.

where $A$ is the peak value in the load curve, $B$ is the valley value in the load curve, $y_{1}(x)$ is the valley membership degree of the load point $x$, and $y_{2}(x)$ is the peak membership degree of the load point $x$.

From Equation (3), the valley membership degree and peak membership degree corresponding to the load of each time can be obtained, and then the period of the load is determined as

$$
\left\{\begin{array}{l}
t(x) \in T_{P}, \text { if } y_{2}(x) \geq \delta \\
t(x) \in T_{L}, \text { if } y_{1}(x) \geq \delta \\
t(x) \in T_{F}, \text { else }
\end{array}\right.
$$

where $T_{P}$ represents the peak hours, $T_{F}$ represents the flat hours, $T_{L}$ represents the valley hours, and $\delta$ is the threshold. When the peak membership value is greater than the threshold, the corresponding $t$ should belong to the peak hours. When the valley membership value is greater than the threshold, the corresponding $t$ should belong to the valley hours. The rest belongs to the flat hours. Assuming the threshold $\delta$ is set to 0.7 [15], the peak-valley division of daily load in Yangjiang is shown in Table VIII.

\section{B. Consumer Response Model}

When the tariff for electric vehicles charging is charged hourly, users will be affected by the price difference between peak and valley hours. The suitable charging hours will be chosen for their actual needs. Psychologically, for a certain threshold between price differences, if it is less than the minimum threshold, consumers will not respond. There is also a maximum threshold for the price difference. If the price difference is greater than the maximum threshold, consumers will not take further response, that is, the load transfer rate $\xi$ will not increase any more. When the price difference is between maximum and minimum threshold, some of consumers will respond. The response (the degree of load transfer) is related to the price difference, for example, a linear function, as shown in Fig. 7. 


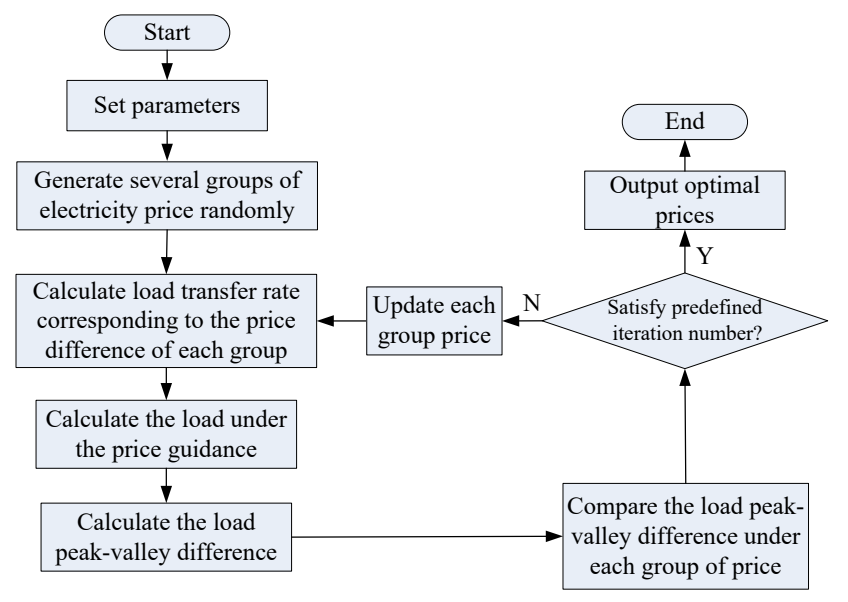

Fig. 8. Flowchart of controlled charging optimization.

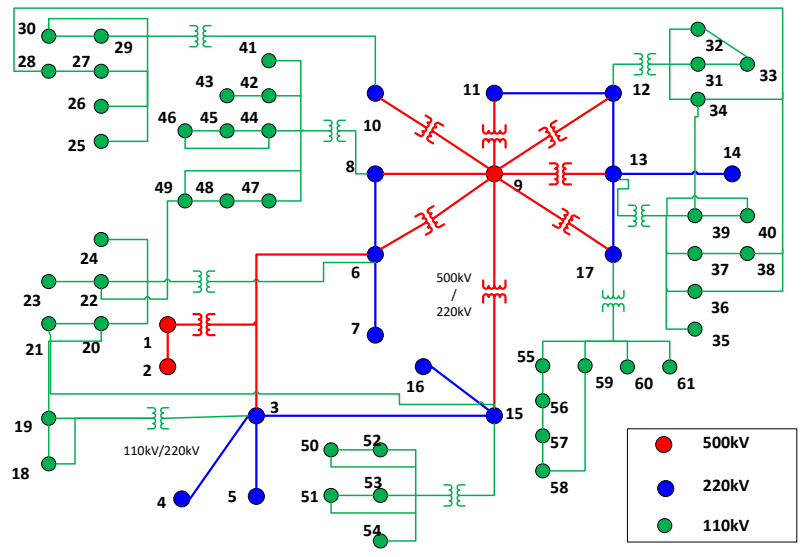

Fig. 9. One-line diagram of the simulated system.

\section{Controlled Charging}

From the above analysis, large-scale introduction of plug-in electric vehicles will increase the load of the power grid. As the charging load increases, the peak-valley difference of the power load will increase continuously. In order to reduce the load increase due to electric vehicle charging on the power grid, the control objective function for electric vehicles controlled charging is to minimize the peak-valley load difference, which is as follows:

$$
\min P=\min \left(P_{\max }-P_{\min }\right)
$$

where $P_{\max }$ and $P_{\min }$ are the maximum and minimum power load after the electric vehicle charging load are added to the original power load, respectively. The controlled charging optimization process is shown in Fig. 8 and the particle swarm optimization is used to conduct the optimization.

The proposed method is implemented on a distribution system in Yangjiang and the single-line diagram of this area is depicted in Fig. 9. The experimental data of charging demand collected from Yangjiang in 2019 is used in the simulation.

From the analysis of the charging load curve in Section II, it can be seen that with the increase in penetration rate in electric private vehicles, the peak power load also increases. Thus the most serious scenario of $15 \%$ penetration rated is tested. In the

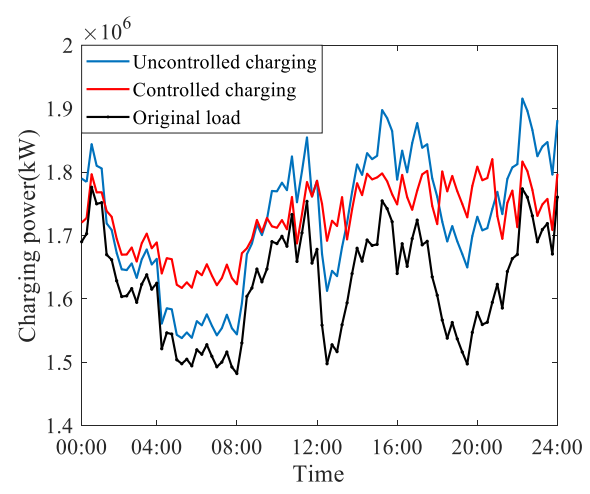

Fig. 10. Comparison between controlled and uncontrolled charging loads of electric vehicles

TABLE IX. LOAD UNDER THE CONTROLLED AND UNCONTROLLED CHARGING

\begin{tabular}{|c|c|c|c|}
\hline $\begin{array}{c}\text { Charging } \\
\text { strategy }\end{array}$ & $\begin{array}{c}\text { Minimum } \\
\text { load/MW }\end{array}$ & $\begin{array}{c}\text { Maximum } \\
\text { load/MW }\end{array}$ & $\begin{array}{c}\text { Peak-valley } \\
\text { difference }\end{array}$ \\
\hline Original load & 1482.1 & 1776 & $16.5 \%$ \\
\hline $\begin{array}{c}\text { Uncontrolled } \\
\text { charging }\end{array}$ & 1538.1 & 1915.9 & $19.7 \%$ \\
\hline $\begin{array}{c}\text { Controlled } \\
\text { charging }\end{array}$ & 1617.1 & 1820.4 & $11.4 \%$ \\
\hline
\end{tabular}

TABle X. Optimal Peak-VAlley-Flat Charging Price

\begin{tabular}{|c|c|c|}
\hline $\begin{array}{c}\text { Peak hours } \\
\text { price/yuan }\end{array}$ & $\begin{array}{c}\text { Flat hours } \\
\text { price/yuan }\end{array}$ & $\begin{array}{c}\text { Valley hours } \\
\text { price/yuan }\end{array}$ \\
\hline 1 & 0.48 & 0.26 \\
\hline
\end{tabular}

planned year, the total number of private vehicles in the region is predicted to be 610,000 , the power of the fast charging spot is $42 \mathrm{~kW}$, the slow charging power is $7 \mathrm{~kW}$ as mentioned, and the construction ratio of the fast charging spot compared to the slow charging spot is $1: 1$. The electricity price in the controlled charging strategy is set between 0.26 yuan and 1.00 yuan, with reference to the electricity price of China Southern Power Grid. The comparison of the charging load between the controlled charging and uncontrolled charging of electric vehicles is shown in Fig. 10, the corresponding power load is shown in Table IX, and the optimal peak-flat-valley charging electricity price obtained by the controlled charging strategy is shown in Table $\mathrm{X}$.

It can be seen from Fig. 10 that there are multiple peaks in the daily load curve of the distribution network. If electric vehicles are under large-scale uncontrolled charging, the original peak power load will increase, making the peak-valley difference much larger, which is not favorable to the economical operation of power grid. After optimizing with the proposed controlled charging strategy, the optimal peak-to-valley charging electricity price is obtained through the particle swarm optimization algorithm. Then the time-of-use electricity price is used to shift the charging load, so as to reduce the peak-to-valley difference of the power load and improve the power system operation and stability.

\section{CONCLUSION}

With the rapid development of electric vehicles, the largescale charging behavior of electric vehicles will inevitably affect 
the distribution network. In this paper, the calculation method of electric vehicle charging load is studied. First, the peak-to-valley hours are divided by the membership function, minimizing the peak-to-valley difference is taken as controlled objective, and the particle swarm optimization algorithm is used to determine the optimal time-of-use electricity price for charging. By comparing the impact of electric vehicles on the power grid under controlled and uncontrolled charging, this paper provides a controlled charging management of electric vehicles connected to the power grid, which has certain practical significance to power network security which is essential for smart city operation.

\section{ACKNOWLEDGMENT}

The authors wish to thank the Guangdong Power Grid Co., Ltd in proving the funding (GDKJ031700KK52180001) to conduct this research.

\section{REFERENCES}

[1] C. S. Lai, L. L. Lai and Q. H. Lai, Smart Grids and Big Data Analytics for Smart Cities, Springer, Oct. 2020.

[2] Campillo, Javier and Vassileva, "Lana.Adoption barriers for electric vehicles: Experiences from early adopters in Sweden," Elsevier J. Energy, vol. 120, pp. 632-641, Feb. 2017

[3] Farahani and F. Hassan, "Improving voltage unbalance of low-voltage distribution networks using plug-in electric vehicles," Elsevier J. Cleaner Prod., vol. 148, pp. 336-346, Apr. 2017.

[4] P. Hanemann, M. Behnert, and T. Bruckner, "Effects of electric vehicle charging strategies on the German power system," Elsevier J. Applied Energy, vol. 203, pp. 608-622, Jun. 2017.

[5] S. Jun, T.T. Lie, and Z. Ramon, "Modelling of large-scale electric vehicles charging demand: a New Zealand case study,” Elsevier J. Elect. Power Syst, vol. 167, pp. 171-182, Feb. 2019.
[6] Munshi, A. Amr and Mohamed, "Unsupervised Nonintrusive Extraction of Electrical Vehicle Charging Load Patterns," IEEE Trans. Ind. Inform., vol. 15, pp. 266-279, Jan. 2019.

[7] M. Rahul, S. Dipti and T. Anupam, "Hybrid Planning Method Based on Cost-Benefit Analysis for Smart Charging of Plug-In Electric Vehicles in Distribution Systems," IEEE Trans. Smart Grid, vol. 10, pp. 523-534, Jan. 2019.

[8] T. U. Solanke and K. Vigna, "A review of strategic charging-discharging control of grid-connected electric vehicles," Elsevier J. Energy Storage, vol. 28, pp. 93-101, Apr. 2020

[9] Z. Jiucai, Jorgenson, and Jennie, "Value to the Grid From Managed Charging Based on California's High Renewables Study," IEEE Trans. Power Syst., vol. 34, pp. 831-840, Mar. 2019.

[10] J. Aaron, T. Brian and S. Brendan, "Comparing the emissions benefits of centralized vs. decentralized electric vehicle smart charging approaches: A case study of the year 2030 California electric grid," Elsevier J. Power Sources, vol. 401, pp. 175-185, Oct. 2018.

[11] S. Bin Humayd and B. Kanka, "Design of Optimal Incentives for Smart Charging Considering Utility-Customer Interactions and Distribution Systems Impact," IEEE Trans. Smart Grid, vol. 10, pp. 1521-1531, Mar. 2019.

[12] Guangdong Statistical Yearbook-2019. Statistics Bureau of Guangdong Province. Beijing: China Statistics Press, 2019.

[13] Yangjiang Electric Vehicle charging Infrastructure Special planning (2016-2020). Yangjiang: Yangjiang Development and Reform Bureau, 2016.

[14] S. Suman and J. Prerna, "Integrated TOU price-based demand response and dynamic grid-to-vehicle charge scheduling of electric vehicle aggregator to support grid stability," Int. Trans. Elect. Energy S., vol. 30, no. 1, pp. 11-22, Jan. 2020

[15] Y. Xinhua, S. Yan, and Z. Huiru, "The modal of peak-off-valley load period division based on threshold optimization," Smart Power, vol. 43, no. 12 , pp. 66-71, Dec. 2015 